\title{
Review: early supported discharge reduces death or dependence after stroke
}

Langhorne P, Taylor G, Murray G, et al. Early supported discharge services for stroke patients: a meta-analysis of individual patients' data. Lancet 2005;365:501-6.

In patients admitted to hospital with stroke, does an early supported discharge (ESD) service with rehabilitation at home provide better outcomes than conventional in-hospital care?

METHODS

Data sources: the Cochrane Specialised Register of Controlled
Trials (to August 2004) was searched and trialists were asked to
describe their intervention and control services and to provide
individual patient data.
Study selection and assessment: randomised controlled trials
(RCTs) that compared an ESD intervention with conventional care
in patients admitted to hospital with stroke. The aim of ESD was to
accelerate discharge from hospital and provide rehabilitation
and regular assistance in a community setting. Quality
assessment of individual trials was based on allocation
concealment and blinding of outcome assessors.
Outcomes: a composite endpoint of death or dependence
(Barthel index < $19 / 20$ or Rankin score $>2$ ). Secondary
outcomes were death; death or need for long term institutional
care; change in activities of daily living (ADL), subjective health
status, or mood or depression; patient satisfaction; caregiver
outcomes (subjective health status, mood score, and satisfaction);
and resource outcomes (length of stay and hospital readmission).

\section{MAIN RESULTS}

11 RCTs ( $\mathrm{n}=1597$, mean or median age range 68-78 y) met the selection criteria. The trials were done in Australia, Canada, Norway, Sweden, Thailand, and the UK. Median follow up was 6 months (range 3-12 mo). 9 RCTs used a concealed randomisation procedure, and 10 RCTs used blinded outcome assessment. The same ESD team coordinated hospital discharge and rehabilitation at home in 7 RCTs; the ESD team coordinated discharge home and immediate postdischarge care but not rehabilitation care in 2 RCTs; and patients received multidisciplinary care in hospital, but post-discharge care was provided by uncoordinated community services or healthcare volunteers in 2 RCTs. Patients who received ESD had greater reductions in death or dependence than patients who received conventional care (table). Groups did not differ for death, but the composite endpoint of death or need for long term institutional care was reduced with ESD (table). Groups did not differ for ADL, subjective health status, or mood scores. Patients who received ESD were more likely to report satisfaction with outpatient services (odds ratio $1.6,95 \%$ CI 1.1 to 2.4 ) (5 RCTs). Caregivers' outcomes did not

For correspondence: Professor P Langhorne, Academic Section of Geriatric Medicine, Royal Infirmary, Glasgow, UK. P.Langhorne@clinmed.gla.ac.uk Sources of funding: Stroke Association and Chest, Heart \& Stroke Scotland. differ between groups. Length of hospital stay was 7.7 days (CI 4.2 to 10.7) shorter in the ESD group (9 RCTs). Hospital readmission rates were similar between groups ( $27 \% \vee 25 \%$ ) (5 RCTs). Significant subgroup interaction existed with the presence or absence of coordinated, multidisciplinary ESD teams. ESD was more effective in patients with moderate than with severe stroke.

\section{CONCLUSION}

In patients admitted to hospital with stroke, an early supported discharge service with rehabilitation at home reduces death and disability more than conventional in-hospital care.

A modified version of this abstract appears in ACP Journal Club.

\section{Commentary}

he benefits of organised stroke services have been clearly shown in previous reviews. ${ }^{1}$ ESD is an approach common to many stroke services, and the rigorous and comprehensive meta-analysis by Langhorne et al can further inform both the design and delivery of services. The benefit of ESD shown in this review does not depend on whether organised stroke unit care is used as a comparison.

Langhorne et al examined the composition of ESD teams within the trials and found a minimal role for nurses: the median number of nurses on ESD teams in the 11 included trials was 0 . It would be interesting to establish whether this is typical of other ESD teams, as it brings into question the wider contribution of nursing to the patient rehabilitation process. The 11 trials were from 6 countries, and the role of nurses in the rehabilitation process may vary internationally.

The conclusion of Langhorne et al highlights the potential benefits of "appropriately resourced and coordinated services." This important point should not be lost on those seeking to develop ESD services. The subgroup analysis also shows that ESD services benefit patients with moderate stroke but may be less suitable for those with severe stroke.

For nurses, this individual patient data meta-analysis indicates the patients most appropriately referred for ESD, whilst also questioning the role of nurses in existing ESD services. Perhaps it serves to highlight that services are most effective when tailored to meet patient needs. Similar to many trials of nurse led care, the professional background of those delivering care seems less important than adequate provision of organisational resources and training.

David Stevenson, RGN, MSc Harrogate Health Care NHS Trust Harrogate, North Yorkshire, UK

1 Stroke Unit Trialists' Collaboration. Cochrane Database Syst Rev $2001 ;(3): C D 000197$

Early supported discharge (ESD) v conventional in-hospital care for stroke*

\begin{tabular}{|c|c|c|c|c|c|}
\hline $\begin{array}{l}\text { Outcomes at a median } \\
\text { of } 6 \text { months }\end{array}$ & Number of trials (n) & ESD & Conventional care & $\operatorname{RRR}(95 \% \mathrm{Cl})$ & NNT (Cl) \\
\hline $\begin{array}{l}\text { Death or dependence } † \\
\text { Death } \ddagger \\
\text { Death or long term } \\
\text { institutional care } \ddagger\end{array}$ & $\begin{array}{r}11(1597) \\
11(1597) \\
9(1398)\end{array}$ & $\begin{array}{c}45 \% \\
8.8 \% \\
18 \%\end{array}$ & $\begin{array}{c}50 \% \\
9.7 \% \\
23 \%\end{array}$ & $\begin{array}{l}11 \%(1 \text { to } 20) \\
9.1 \%(-23 \text { to } 33) \\
21 \%(3 \text { to } 36)\end{array}$ & $\begin{array}{l}19(10 \text { to } 157) \\
\text { Not significant } \\
21(12 \text { to } 175)\end{array}$ \\
\hline
\end{tabular}

*Abbreviations defined in glossary.

TRRR, NNT, and $\mathrm{Cl}$ calculated from data in article.

†Numbers calculated from data provided by author. 